\title{
Chitosan as heterogeneous catalyst in Michael additions: the reaction of cinnamonitriles with active methylene moieties and phenols
}

\author{
Hamad M. Al-Matar, ${ }^{\mathrm{a}}$ Khaled D. Khalil, ${ }^{\mathrm{a}}$ Herbert Meier, ${ }^{\mathrm{b}}$ Heinz Kolshorn, ${ }^{\mathrm{b}}$ and \\ Mohamed H. Elnagdi ${ }^{a}$ \\ ${ }^{a}$ Department of Chemistry; Faculty of Science; Kuwait University; P.O. Box 5969; \\ Safat 13060 Kuwait \\ ${ }^{b}$ Institute of Organic Chemistry, Johannes Gutenberg-University, Mainz, Germany
}

E-mail: almatarc60@hotmail.com

\begin{abstract}
The reaction of active methylene moieties, pyrazolones, thiazolylacetonitriles, phenols and alkyl pyridazinones with benzylidene-malononitrile in ethanol in presence of chitosan afforded aminopyrancarbonitriles, pyranopyrazole, thiazolopyridines, chromenes, and pthalazines in yields comparable to those obtained in ethanolic piperidine. Much lower yields were obtained in aqueous solutions.
\end{abstract}

Keywords: Chitosan, piperidine, aminopyrancarbonitrile, benzylidene-malononitrile, chromenes

\section{Introduction}

In 1976 one of us reported the first addition of an active methylene reagent to cinnamonitriles. ${ }^{1}$ Since then plenty of acyclic active methylenes, ${ }^{2-5}$ cyclic active methylenes, ${ }^{6-7}$ functionally substituted alkylazoles, ${ }^{8-11}$ alkylazinylcarbonitriles ${ }^{12-13}$ as well as other nucleophilic reagents have been added during the 1970's and 1980's. ${ }^{14-18}$ Generally, reactions of benzylidene-malononitrile with active methylene ketones give aminopyrancarbonitriles. Alternatively, cyclic ketones have been reported to yield either tetrahydronaphthalenes or tetrahydrobenzopyrans ${ }^{7,16,19}$ depending on substitution pattern. Phenols and naphthols are established to yield naphthopyrans ${ }^{16,17}$ while alkyl heteroaromatic carbonitriles are established to yield benzoazines. ${ }^{20}$ These reactions have been conducted usually in ethanolic solution in the presence of catalytic amounts of piperidine or in pyridine as both solvent and basic catalyst. Recent interest in these reactions has been revived ${ }^{21}$ with the aim of substituting piperidine or pyridine by an ecologically more acceptable catalysis including water, alkali metal salts and basic 
alumina. $^{22}$ It occurred to us in light of this of value, to investigate these additions that were mostly reported from one of our laboratories to see if chitosan (Figure 1), a naturally occurring ecofriendly polymer can be used as a heterogeneous catalyst thus affording a new environmentally benign route to compounds reported above. Use of chitosan as a basic catalyst has found recent interest. ${ }^{23}$ All the results reported in the literature on the use of chitosan in catalysis dealt with the properties of complexation of the amino groups ${ }^{24-30}$ or with its hydrophilic character for supported aqueous phase catalysis. $^{31,32}$

Moreover, it seemed also of value to inspect in light of spectroscopic methods (NOE, HMQC, HMBC) that were not used in the past for the actual product structure determination in these additions. From time to time different authors came to conflicting conclusions.

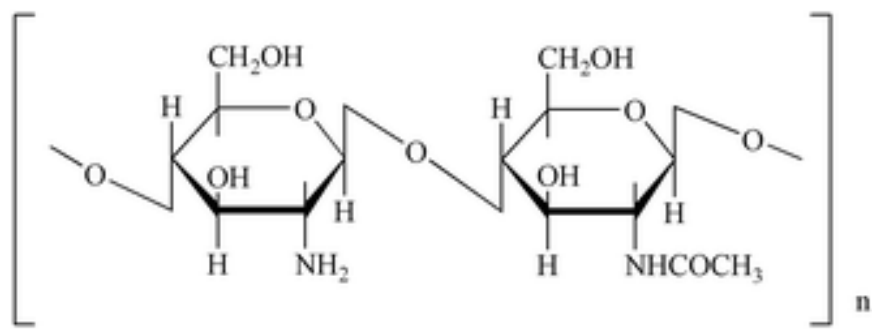

Figure 1

\section{Results and Discussion}

Benzylidene-malononitrile 1 was reacted with ethyl acetoacetate in the presence of piperidine as reported in our initial paper $^{3}$ to yield 2 in $67 \%$ yields. Repeating the reaction in water afforded 2 in much lower yield (24\%) while in water and piperidine the product was formed in $45 \%$ yield. In presence of chitosan/water, the product was formed in $43 \%$ yield. Utilizing chitosan in ethanol afforded the product in $59 \%$ yield.

Compound 1 was reacted with cyclohexanone to yield 3A. Again yields under different conditions were measured and found to follow the same sequence demonstrated for the reaction of 1 with ethyl acetoacetate to yield 2 (Scheme 1). A pair of enantiomers 3A was formed $[(4 R, 4 \mathrm{a} S)$ and $(4 S, 4 \mathrm{a} R)]$. The obtained spectra do not show any hints for diastereomeric pair of enantiomers $(4 R, 4 \mathrm{a} R)$ and $(4 S, 4 \mathrm{a} S)$. The hydrogen atoms on C-4 and $\mathrm{C}-4 \mathrm{a}$ are trans and have both axial position $\left({ }^{3} \mathrm{~J}=12.3 \mathrm{~Hz}\right)$. Thus the structure 3B published by Elgemeie et $a .^{33}$ and by Gewald and Schill $^{34}$ is not correct but $3 \mathbf{A}$ previously published by Polansky et $a .^{35}$ and by El-Sakka et al. ${ }^{36}$ is the correct one. The ortho protons and ortho carbon atoms of the phenyl group have different $\delta$ values in the NMR spectroscopy at room temperature because of the "frozen" rotation of the phenyl 
group. 1-Naphthol and 2-naphthol did not react with $\mathbf{1}$ at all in water but reacted with $\mathbf{1}$ in ethanol in presence of chitosan to give $4 \mathbf{a}, \mathbf{b}$ in 71 and $65 \%$ yields respectively (cf. Scheme 1).

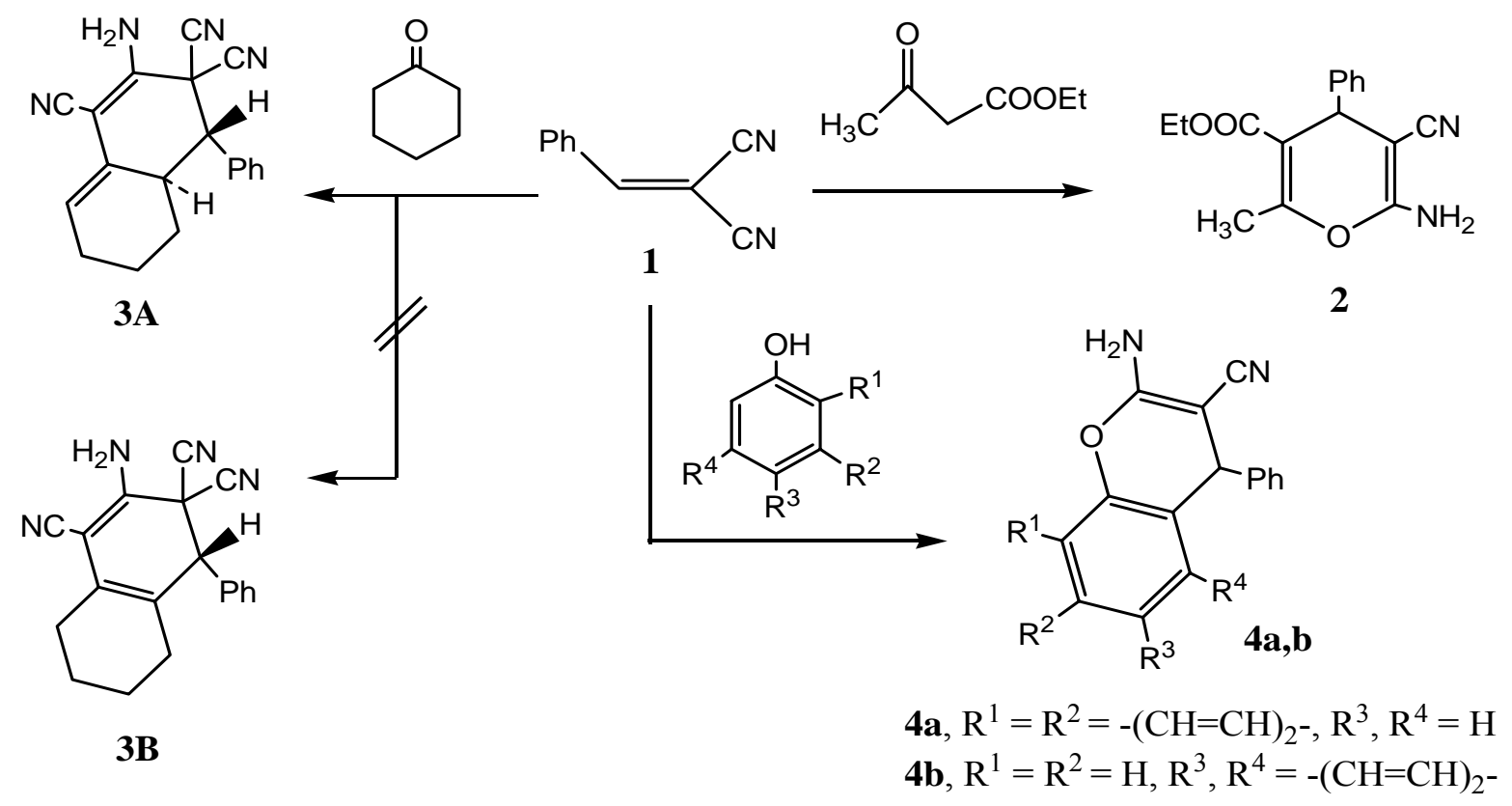

\section{Scheme 1}

We have reported that ${ }^{16}$ resorcinol reacts with 1 to yield 5 in ethanolic piperidine (71 $\%$ yield). However Abdel-Latif ${ }^{37}$ has assigned structure 6 for this same product. AlMousawi et al. ${ }^{38}$ have later indicated through analysis of ${ }^{1} \mathrm{H}$ NMR data that the actual structure is really 5 initially suggested by one of us. We have now established structure 5 based on NOE difference measurements. Thus irradiating H-4- proton in 5 at $\delta 4.62 \mathrm{ppm}$ enhanced the signal intensity of the aromatic proton (H-5) at $\delta 7.16 \mathrm{ppm}$ while if reaction product is 6 such an enhancement would have not been observed. The product was also obtained in $69 \%$ yield in ethanol in presence of chitosan (Scheme 2). 


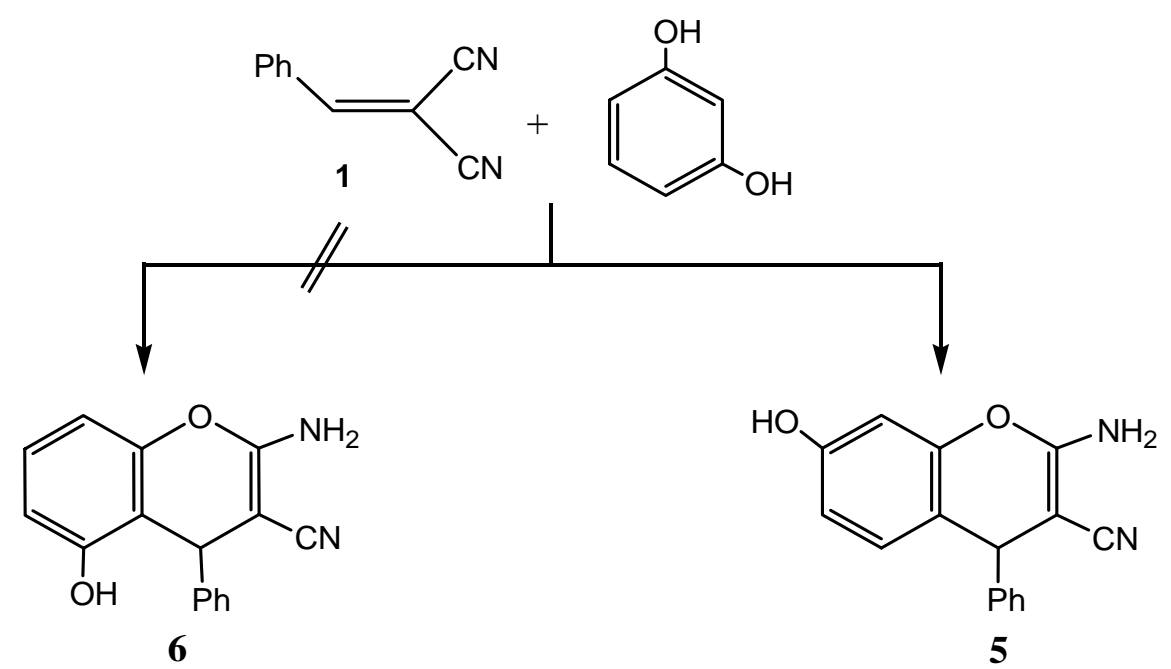

\section{Scheme 2}

Similar to reported reaction of $\mathbf{1}$ with pyrazolones, ${ }^{6 a, 39}$ compound 1 reacted with 3methylpyrazolone 7 in ethanol in the presence of chitosan to yield a pyranopyrazole derivative 8 ( $84.2 \%$ yield) (Scheme 3 ). This may exist in $1 H$ or $2 H$ forms (8A or 8B). Structure $\mathbf{8 A}$ is established through inspection of result by NOE experiments. Thus upon irradiation into the methyl signal at $\delta 1.77 \mathrm{ppm}$ a strong effect for the NH proton at 12.10 ppm was revealed. This is a proof for the major position of the $\mathrm{NH}$ proton on $\mathrm{N}-2$. A fast equilibrium with $\mathbf{8 B}$ as minor components cannot be excluded at room temperature.

Thiazolylacetonitrile $\mathbf{9}$ has been reported to react with $\mathbf{1}$ in ethanolic piperidine to yield 10 (68\% yield). ${ }^{8}$ A similar conclusion has been reached independently by El-Hag Ali et al. ${ }^{40}$ who ignored reference to the original paper published by Elnagdi et al. ${ }^{8}$ Recently however we read a paper suggesting formation of pyranothiazoles $\mathbf{1 1}$ rather than thiazolopyridines in a similar reaction. ${ }^{41}$ Thus, we have measured ${ }^{1} \mathrm{H}$ NMR, ${ }^{13} \mathrm{C}$ NMR, HMBC and HMQC. It was noted in HMBC that the carbonyl carbon atom at $165 \mathrm{ppm}$ is coupled to the arylmethylene proton at $7.85 \mathrm{ppm}$. The coupling constant value of $\delta 6.6 \mathrm{~Hz}$ suggested that the molecule is a thiazolo[3,2-a]pyridine with an arylmethylene moiety that adopts the Z-configuration. The reaction of $\mathbf{1}$ with $\mathbf{9}$ could also be performed in ethanol in presence of chitosan to give $\mathbf{1 0}$ in $63 \%$ yields very similar to that reported for reaction in ethanolic piperidine (Scheme 3). 


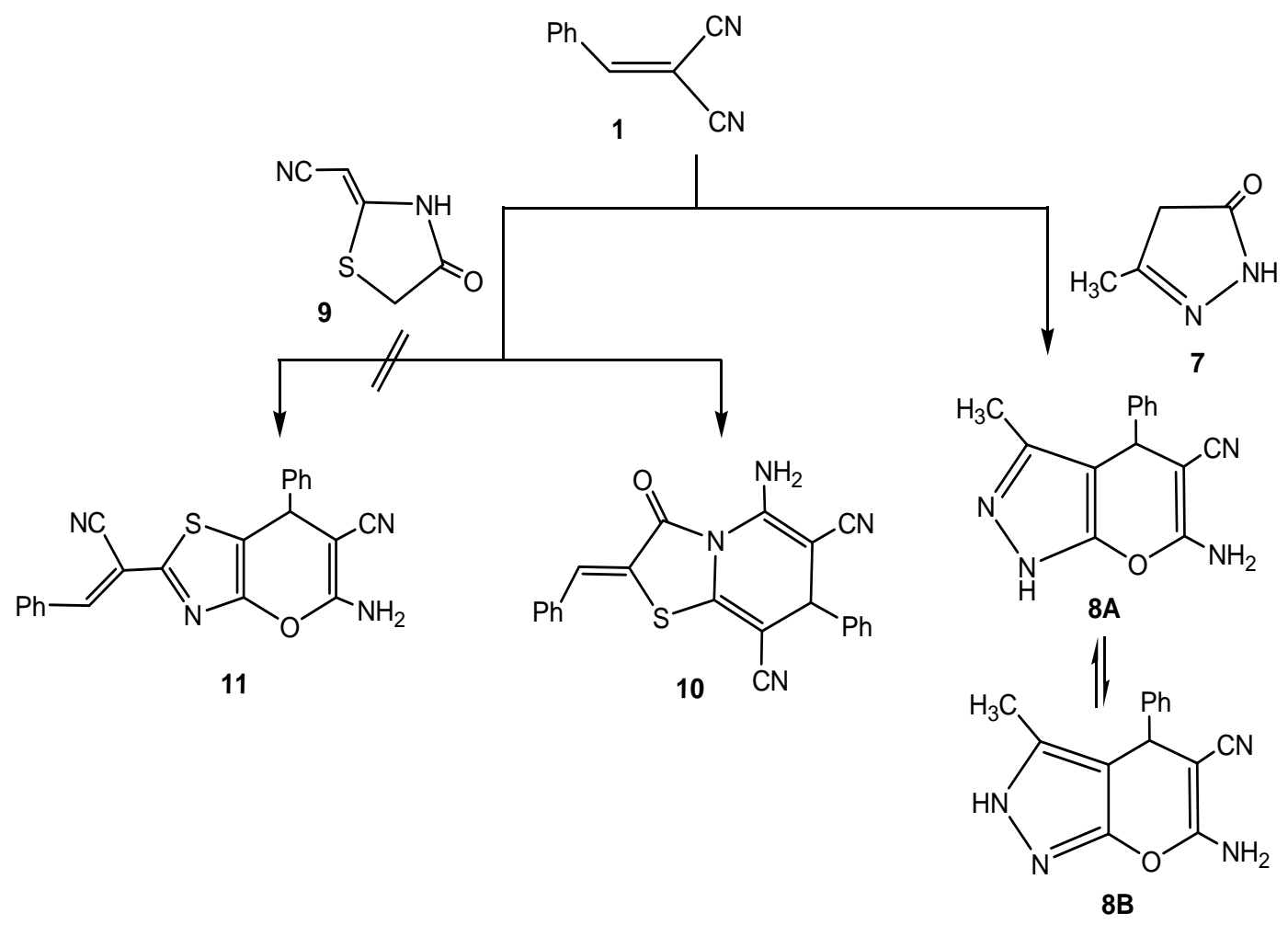

\section{Scheme 3}

Again similar to reported formation of 13a-c from reactions of $\mathbf{1 2 a - c}$ with $\mathbf{1}$ in pyridine $\left(67,61\right.$ and $76 \%$ yields respectively), ${ }^{42}$ compounds 12 a-c reacted with 1 in ethanol in the presence of chitosan to afford 13a-c with $65 \%, 55 \%$ and $71 \%$ yields respectively (Scheme 4).<smiles>[R]Cc1c([R])nn(-c2ccc(Cl)cc2)c(=O)c1C#N</smiles>

12a-c

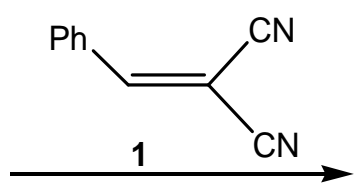

12a; $\mathrm{R}^{1}=\mathrm{H}, \mathrm{R}^{2}=\mathrm{H}$

12b; $\mathrm{R}^{1}=\mathrm{H}, \mathrm{R}^{2}=\mathrm{CH}_{3}$

12c; $R^{1}=$ COOEt, $R^{2}=H$<smiles>[R]c1nn(-c2ccc(Cl)cc2)c(=O)c2c(N)c(C#N)c(-c3ccccc3)c([R])c12</smiles>

13a; $\mathrm{R}^{1}=\mathrm{H}, \mathrm{R}^{2}=\mathrm{H}$

13b; $\mathrm{R}^{1}=\mathrm{H}, \mathrm{R}^{2}=\mathrm{CH}_{3}$

13c; $R^{1}=$ COOEt, $R^{2}=H$

Scheme 4 
We have found that the reaction of $\mathbf{1 6}$, obtained by following the literature procedure ${ }^{43}$ via condensing $\mathbf{1 4}$ and 15, with $\mathbf{1}$ afforded $\mathbf{1 7}$ in $43 \%$ yield in the presence of chitosan in ethanol (Scheme 5).<smiles>[CH]C(=O)c1ccccc1</smiles>

14<smiles>N#CCC#N</smiles>

15<smiles>CCCCCC</smiles>

16

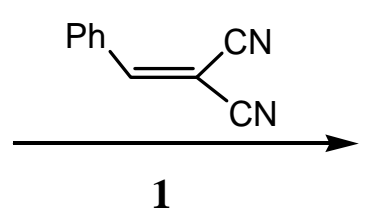<smiles>N#Cc1c(-c2ccccc2)cc(-c2ccccc2)c(C#N)c1N</smiles>

17

\section{Scheme 5}

The reaction of 2-amino-1-propene-1,1,3-tricarbonitrile $\mathbf{1 8}$ with $\mathbf{1}$ gave the addition product 20 in ethanol in presence of chitosan (63\% yield). Similar addition products were reported earlier by us and initially assigned to structure $19^{18}$ but later corrected and assigned to structure 20 which was believed to be present in equilibrium with $21 .{ }^{44}$ Now, ${ }^{1} \mathrm{H}$ and ${ }^{13} \mathrm{C}$ NMR measurements indicated the presence of only one form namely 20 . Due to the rotation of the exo-methylene group, which is relatively slow in terms of the NMR time scale, the two geminal $\mathrm{CN}$ groups give a very broad ${ }^{13} \mathrm{C}$ signal at about $120 \mathrm{ppm}$. At higher temperature a sharp signal at $119.6 \mathrm{ppm}$ can be observed in $\mathrm{CD}_{3} \mathrm{SOCD}_{3}$ (Scheme $6)$.<smiles>CCCc1c(C#N)c(C#N)c(C#N)c(-c2ccccc2)c1C#N</smiles><smiles>CC(C)(C)CC[C@H](N)c1c(N)c(=C(C#N)C#N)nc(N)c1=Cc1ccccc1</smiles>

20

21

\section{Scheme 6}

\section{Conclusions}

Benzylidene-malononitrile reacts with active methylenes, electron rich aromatics as well as alkylpyridazinylcarbonitriles in ethanol in presence of chitosan to yield the same 
products which were obtained earlier by us in ethanolic piperidine or in pyridine solution in comparable yields. Moreover, conclusive spectroscopic evidence for structures for which conflicting results were reported could be offered through modern spectral measurements.

\section{Experimental Section}

General Procedures. Infrared spectra $(\mathrm{KBr})$ were determined on a Perkin-Elmer 2000 FT-IR system. ${ }^{1} \mathrm{H}$ NMR and ${ }^{13} \mathrm{C}$ NMR were determined on a Bruker DPX $600 \mathrm{MHz}$ spectrometer in DMSO- $d_{6}$ as solvent and using TMS as internal standard. Mass spectra were measured on MS 30 and MS 9 (AEI) spectrometers, with EI $70 \mathrm{eV}$. Chitosan was obtained from Tokyo Kasei Kogyo Co., LTD, Tokyo, Japan and $0.1 \mathrm{~g}$ chitosan was used as a catalyst in every experiment.

\section{Reaction of 1 with ethylacetoacetate and with cyclohexanone}

Method A. A mixture of benzylidene-malononitrile (1) $(1.54 \mathrm{~g}, 10.0 \mathrm{mmol})$ with either ethylacetoacetate or cyclohexanone $(10.0 \mathrm{mmol})$ in the presence of $50 \mathrm{~mL}$ water was refluxed for $3 \mathrm{~h}$. The solid product, so formed, was filtered of and recrystallized from ethanol.

Method B. A mixture of the above components in $50 \mathrm{~mL}$ water in the presence of catalytic amount of chitosan was refluxed for $3 \mathrm{~h}$. The crude product, so formed, was collected by filtration and then recrystallized from ethanol.

Method C. A mixture of same components in $50 \mathrm{~mL}$ (96\%) ethanol in the presence of catalytic amount of chitosan was refluxed for $3 \mathrm{~h}$. The reaction mixture was evaporated then triturated with water. The solid product, so formed, was recrystallized from ethanol.

Method D. A mixture of the same components in $50 \mathrm{~mL}(96 \%)$ ethanol in the presence of piperidine was refluxed for $3 \mathrm{~h}$. The reaction mixture was treated as described above and the solid product was crystallized from ethanol.

6-Amino-5-cyano-2-methyl-4-phenyl-4H-pyran-3-carboxylic acid ethyl ester (2). ${ }^{4 b}$ This compound was obtained as yellow crystals; $\operatorname{IR}(\mathrm{KBr}): v=1691(\mathrm{C}=\mathrm{O}), 2190(\mathrm{CN}), 3329,3404$ $\left(\mathrm{NH}_{2}\right) \mathrm{cm}^{-1},{ }^{1} \mathrm{H}$ NMR (DMSO- $\left.d_{6}\right): \delta=1.03\left(\mathrm{t}, 3 \mathrm{H}\right.$, ester $\left.\mathrm{CH}_{3}\right), 2.32\left(\mathrm{~s}, 3 \mathrm{H}, 2-\mathrm{CH}_{3}\right), 3.98(\mathrm{AB}$ of $\left.\mathrm{ABX}_{3}, 2 \mathrm{H}, \mathrm{OCH}_{2}\right), 4.30(\mathrm{~s}, 1 \mathrm{H}, 4-\mathrm{H}), 6.95\left(\mathrm{~s}, 2 \mathrm{H}, \mathrm{NH}_{2}\right), 7.15$ (m, 2H, o-H, Phenyl), $7.22(\mathrm{~m}, 1 \mathrm{H}$, p-H, Phenyl), 7.32 (m, 2H, m-H, Phenyl); ${ }^{13} \mathrm{C}$ NMR (DMSO-d $\left.d_{6}\right): \delta=13.7\left(\mathrm{CH}_{3}\right.$ of $\mathrm{CO}_{2} \mathrm{C}_{2} \mathrm{H}_{5}$ ), $18.1\left(2-\mathrm{CH}_{3}\right), 38.8(\mathrm{C}-4), 57.3(\mathrm{C}-5), 60.1\left(\mathrm{O}-\mathrm{CH}_{2}\right), 107.3(\mathrm{C}-3), 119.6(\mathrm{CN}), 126.8(p-\mathrm{C}$, Phenyl), 127.1 (o-C, Phenyl), 128.4 (m-C, Phenyl), 144.8 (i-C, Phenyl), 156.5, 158.5 (C-2, C-6), 165.4 (C=O); MS, m/z (\%), $284.2\left(\mathrm{M}^{+}, 70\right), 207.1$ (100), 179.1 (63).

\% Yields: Method A (24), Method B (43), Method C (59), and Method D (67).

2-Amino-4-phenyl-4a,5,6,7-tetrahydro-4H-naphthalene-1,3,3-tricarbonitrile $\quad$ (3). ${ }^{36}$ This compound was obtained as yellow crystals; IR $(\mathrm{KBr}): v=1650$ (olefinic $\mathrm{C}=\mathrm{C}$ ), $2211(\mathrm{CN}), 2254$ (CN) 3341, $3420\left(\mathrm{NH}_{2}\right) \mathrm{cm}^{-1},{ }^{1} \mathrm{H}$ NMR (DMSO- $\left.d_{6}\right): \delta=0.84(\mathrm{~m},, 1 \mathrm{H}, 5-\mathrm{H}), 1.44(\mathrm{~m}, 2 \mathrm{H}, 5-\mathrm{H}$, 6-H), $1.66(\mathrm{~m}, 1 \mathrm{H}, 6-\mathrm{H}), 2.04(\mathrm{~m}, 1 \mathrm{H}, 7-\mathrm{H}), 2.17(\mathrm{~m}, 1 \mathrm{H}, 7-\mathrm{H}), 2.80(\mathrm{~m}, 1 \mathrm{H}, 4 \mathrm{a}-\mathrm{H}), 3.52\left(\mathrm{~d},{ }^{3} \mathrm{~J}=\right.$ 
$12.3 \mathrm{~Hz}, 1 \mathrm{H}, 4-\mathrm{H}), 5.72$ ("s", 1H, 8-H), 7.37 (s, 2H, NH ), 7.41 (m, 3H, m-H, p-H, Phenyl), 7.48 (m, 1H, o-H, Phenyl), 7.59 (m, 1H, o-H, Phenyl); ${ }^{13} \mathrm{C}$ NMR (DMSO-d $\left.d_{6}\right): \delta=21.0(\mathrm{C}-6), 24.9(\mathrm{C}-$ 7), 27.0 (C-5), 33.8 (C-4a), 42.9 (C-3), 50.5 (C-4), 81.5 (C-1), 112.4 (3-CN), 112.6 (3-CN), 116.2 (1-CN), 120.3 (C-8), 126.9 (o-C, Phenyl), 128.6 (m-C, Phenyl), 128.8 (C-8a), 128.9 (p-C, Phenyl), 132.4 (o-C, Phenyl), 134.6 (i-C, Phenyl), 143.6 (C-2); MS, m/z (\%), $300.2\left(\mathrm{M}^{+}, 100\right)$, 209.1 (82), 91.1 (93).

\% Yields: Method A (20), Method B (36), Method C (55), and Method D (64).

\section{Synthesis of naphthopyrans 4a,b and benzopyrane 5}

Method A. A mixture of benzylidene-malononitrile (1) (1.54 g, $10.0 \mathrm{mmol})$, with either 1-, 2naphthol or resorcinol $(10.0 \mathrm{mmol}$ of each) in the presence of $50 \mathrm{~mL}$ water was refluxed for 3 hrs. The solid product formed was collected by filtration and recrystallized from ethanol.

Method B. A mixture of the above components in $50 \mathrm{~mL}$ water in the presence of catalytic amount of chitosan was refluxed for $3 \mathrm{~h}$. The solid product was collected and recrystallized as described before.

Method C. A mixture of same components in $50 \mathrm{~mL}(96 \%)$ ethanol in the presence of catalytic amount of chitosan was refluxed for $3 \mathrm{~h}$. The solution was then evaporated in vacuum and remained product was treated as previously mentioned in method $\mathbf{C}$.

Method D. A mixture of same components in $50 \mathrm{~mL}(96 \%)$ ethanol in the presence of piperidine was refluxed for $3 \mathrm{~h}$. The resulting reaction mixture was evaporated in vacuum and the remained product was triturated with water and crystallized from ethanol.

2-Amino-4-phenyl-4H-benzo[h]chromene-3-carbonitrile (4a). ${ }^{16}$ This compound was obtained as yellow crystals; IR $(\mathrm{KBr}): v=1605(\mathrm{Ar} \mathrm{C}=\mathrm{C}), 1656$ (olefinic $\mathrm{C}=\mathrm{C}), 2205(\mathrm{CN}), 3303,3448$ $\left(\mathrm{NH}_{2}\right) \mathrm{cm}^{-1} ;{ }^{1} \mathrm{H}$ NMR (DMSO- $\left.d_{6}\right): \delta=4.90(\mathrm{~s}, 1 \mathrm{H}, 4-\mathrm{H}), 7.11\left(\mathrm{~d},{ }^{3} J=8.5 \mathrm{~Hz}, 1 \mathrm{H}, 5-\mathrm{H}\right), 7.56 \mathrm{~m}$, $2 \mathrm{H} / 7.64, \mathrm{t}, 1 \mathrm{H} / 7.88, \mathrm{~d}, 1 \mathrm{H} / 8.27, \mathrm{~d}, 1 \mathrm{H}(6-\mathrm{H}, 7-\mathrm{H}, 8-\mathrm{H}, 9-\mathrm{H}, 10-\mathrm{H}), 7.18\left(\mathrm{~s}, 2 \mathrm{H}, \mathrm{NH}_{2}\right), 7.24$ (m, 1H, p-H, Phenyl), 7.25 (m, 2H, o-H, Phenyl), 7.32 (m, 2H, m-H, Phenyl); ${ }^{13} \mathrm{C}$ NMR (DMSO- $\left.d_{6}\right)$ : $\delta=40.9$ (C-4), 56.3 (C-3), 117.9, 120.7, 122.7, 123.9, 126.2, 126.6, 126.7, 126.9, 127.6, 132.7 (C-4a, C-5, C-6, C-6a, C-7, C-8, C-9, C-10, C-10a, p-C, Phenyl), 120.4 (CN), 127.6 (o-C, Phenyl), 128.7 (m-C, Phenyl), 142.7, 145.6 (C-10b, i-C, Phenyl), 160.1 (C-2); MS, m/z (\%), $298.1\left(\mathrm{M}^{+}, 75\right), 221.1$ (100), 77 (10).

\% Yields: Method A (Nil), Method B (Nil), Method C (71), and Method D (74)

3-Amino-1-phenyl-1H-benzo[f]chromene-2-carbonitrile (4b). ${ }^{16}$ This compound was obtained as yellow crystals; $\mathrm{IR}(\mathrm{KBr}): v=1590(\mathrm{Ar}-\mathrm{C}=\mathrm{C}), 1640$ (Olefinic $\mathrm{C}=\mathrm{C}), 2183(\mathrm{CN}), 3340,3434$ $\left(\mathrm{NH}_{2}\right) \mathrm{cm}^{-1} ;{ }^{1} \mathrm{H}$ NMR $\left(\mathrm{DMSO}-d_{6}\right): \delta=5.32(\mathrm{~s}, 1 \mathrm{H}, 1-\mathrm{H}), 7.05\left(\mathrm{~s}, 2 \mathrm{H}, \mathrm{NH}_{2}\right), 7.14(\mathrm{~m}, 1 \mathrm{H}, p-\mathrm{H}$, Phenyl), 7.21 (m, 2H, o-H, Phenyl), 7.26 (m, 2H, $m-\mathrm{H}$, Phenyl), 7.36/7.93 (AB, ${ }^{3} J=8.9 \mathrm{~Hz}, 2 \mathrm{H}$, 5-H, 6-H), $7.42(\mathrm{~m}, 2 \mathrm{H}, 8-\mathrm{H}, 9-\mathrm{H}), 7.85(\mathrm{~m}, 1 \mathrm{H}, 10-\mathrm{H}), 7.93(\mathrm{~m}, 1 \mathrm{H}, 7 \mathrm{H}) .{ }^{13} \mathrm{C}$ NMR (DMSO-d $)$ : $\delta=38.1(\mathrm{C}-1), 58.0(\mathrm{C}-2), 115.7,116.7,123.6,124.9,126.6,127.0,128.4,129.5,130.2,130.8$ (C-5, C-6, C-6a, C-7, C-8, C-9, C-10, C-10a, C-10b, p-C, Phenyl), 120.4 (CN), 127.0 (o-C, Phenyl), 128.7 (m-C, Phenyl), 145.7, 146.8 (C-4a, i-C, Phenyl), 159.7 (C-3); MS, m/z (\%), 298.2 $\left(\mathrm{M}^{+}, 70\right), 221.1$ (100), 77 (8). 
\% Yields: Method A (Nil), Method B (Nil), Method C (65), and Method D (66)

2-Amino-7-hydroxy-4-phenyl-4H-chromene-3-carbonitrile $\quad$ (5). ${ }^{16}$ This compound was obtained as yellow crystals; $\mathrm{IR}(\mathrm{KBr}): v=1590(\mathrm{Ar} \mathrm{C}=\mathrm{C}), 1653$ (olefinic $\mathrm{C}=\mathrm{C}), 2182(\mathrm{CN}), 3220$, $3337\left(\mathrm{NH}_{2}\right), 3400(\mathrm{OH}) \mathrm{cm}^{-1} .{ }^{1} \mathrm{H}$ NMR (DMSO-d $): \delta=4.63(\mathrm{~s}, 1 \mathrm{H}, 4-\mathrm{H}), 6.43$ ("s", 1H, 8-H), $6.49(\mathrm{~m}, 1 \mathrm{H}, 6-\mathrm{H}), 6.81(\mathrm{~m}, 1 \mathrm{H}, 5-\mathrm{H}), 6.88\left(\mathrm{~s}, 2 \mathrm{H}, \mathrm{NH}_{2}\right), 7.17$ (m, 2H, o-H, Phenyl), 7.21 (m, $1 \mathrm{H}, p-\mathrm{H}$, Phenyl), 7.31 (m, 2H, m-H, Phenyl), $9.76(\mathrm{~s}, 1 \mathrm{H}, \mathrm{OH}) ;{ }^{13} \mathrm{C}$ NMR (DMSO- $\left.d_{6}\right): \delta=40.1$ (C-4), 56.3 (C-3), 102.1 (C-8), 112.3 (C-6), 113.7 (C-5), 120.6 (CN), 126.6 (p-C, Phenyl), 127.3 (o-C, Phenyl), 128.5 (m-C, Phenyl), 129.8 (C-5), 146.3, 148.9 (C-8a, i-C, Phenyl), 157.0 (C-7), 160.2 (C-2); MS, m/z (\%), $264.1\left(\mathrm{M}^{+}, 75\right), 187.1$ (100), 77 (43).

\% Yields: Method A (15), Method B (24), Method C (69), and Method D (71)

Synthesis of 6-amino-3-methyl-4-phenyl-1,4-dihydro-pyrano[2,3-c]pyrazole-5carbonitrile (8) ${ }^{6 a}$

Method A. A mixture of benzylidene-malononitrile (1) (1.54 g, $10.0 \mathrm{mmol})$ and 4-methyl-5pyrazolone $(0.98 \mathrm{~g}, 10.0 \mathrm{mmol})$ in the presence of $50 \mathrm{ml}$ water was refluxed for $3 \mathrm{~h}$. The solid product, so formed, was collected by filtration and crystallized from dioxane.

Method B. A mixture of the above components in $50 \mathrm{~mL}$ water in the presence of catalytic amount of chitosan was refluxed for $3 \mathrm{~h}$. The solid product, so formed, was purified and chitosan was removed through recrystallization from ethanol.

Method C. A mixture of same components in $50 \mathrm{~mL}(96 \%)$ ethanol in the presence of catalytic amount of chitosan was refluxed for $3 \mathrm{~h}$ and the reaction mixture was treated as in method $\mathbf{B}$.

Method D. A mixture of same components in $50 \mathrm{~mL}(96 \%)$ ethanol in the presence of piperidine was refluxed for $3 \mathrm{~h}$ and the reaction mixture was treated as described above.

6-Amino-3-methyl-4-phenyl-2,4-dihydro-pyrano[2,3-c]pyrazole-5-carbonitrile (8). Compound 8A, yellow crystals, exists in this major tautomeric form. A fast equilibrium with 6-amino-3methyl-4-phenyl-1,4-dihydro-pyrano[2,3-c]pyrazole-5-carbonitrile as minor tautomer is at room temperature possible. IR $(\mathrm{KBr}): v=1597$ (aromatic $\mathrm{C}=\mathrm{C}$ ), 1649 (olefinic $\mathrm{C}=\mathrm{C}), 2192(\mathrm{CN}), 3171$ and $3373\left(\mathrm{NH}_{2}\right) \mathrm{cm}^{-1} ;{ }^{1} \mathrm{H}$ NMR (DMSO-d $): \delta=1.77\left(\mathrm{~s}, 3 \mathrm{H}, \mathrm{CH}_{3}\right), 4.58(\mathrm{~s}, 1 \mathrm{H}, 4-\mathrm{H}), 6.88(\mathrm{~s}$, $2 \mathrm{H}, \mathrm{NH}_{2}$ ), 7.16 (m, 2H, o-H, Phenyl), 7.21 (m, 1H, p-H, Phenyl), 7.31 (m, 2H, m-H, Phenyl), 12.10 (s, 1H, 2-H); ${ }^{13} \mathrm{C}$ NMR (DMSO-d $): \delta=9.8\left(\mathrm{CH}_{3}\right), 36.2$ (C-4), 57.2 (C-5), 97.7 (C-3a), 120.8 (CN), 126.7 (p-C, Phenyl), 127.5 (o-C, Phenyl), 128.5 (m-C, Phenyl), 135.6 (C-3), 144.5 (i-C, Phenyl), 154.8 (C-7a), 160.9 (C-6). MS, m/z (\%), $253.1\left(\mathrm{M}^{+}\right.$, ), 175.1 (100), 77 (6).

\% Yields: Method A (63), Method B (80), Method C (84), and Method D (83).

\section{5-Amino-2-(Z)-benzylidene-3-oxo-7-phenyl-2,3-dihydro-7H-thiazolo[3,2-a]pyridine-6,8- dicarbonitrile (10) ${ }^{8}$}

Method A. A mixture of benzylidene-malononitrile (1) (1.54 g, $10.0 \mathrm{mmol})$, (4-oxo-thiazolidin2-ylidene)acetonitrile $(1.4 \mathrm{~g}, 10.0 \mathrm{mmol})$ in the presence of $50 \mathrm{~mL}$ water was heated under reflux for $3 \mathrm{~h}$ and the product was collected by filtration and purified by recrystallization from ethanol. 
Method B. A mixture of the above components in $50 \mathrm{~mL}$ water in the presence of catalytic amount of chitosan was refluxed for $3 \mathrm{~h}$. The reaction mixture was subjected to same previously mentioned treatment.

Method C. A mixture of same above components in $50 \mathrm{~mL}(96 \%)$ ethanol in the presence of catalytic amount of chitosan was refluxed for $3 \mathrm{~h}$ and the formed product was treated as described before.

Method D. A mixture of same components in $50 \mathrm{~mL}(96 \%)$ ethanol in the presence of piperidine was refluxed for $3 \mathrm{~h}$. The reaction mixture was treated as described above and the product was recrystallized from ethanol.

Compound 10 was obtained as yellow crystals. IR (KBr): $v=1619$ ( $\mathrm{Ar} \mathrm{C}=\mathrm{C}$ ), 1655 (olefinic $\mathrm{C}=\mathrm{C}), 2197(\mathrm{CN}), 3286,3382\left(\mathrm{NH}_{2}\right) \mathrm{cm}^{-1} .{ }^{1} \mathrm{H}$ NMR (DMSO-d $): \delta=4.56(\mathrm{~s}, 1 \mathrm{H}, 7-\mathrm{H}), 7.34(\mathrm{~m}$, 1H, p-H, 7-Phenyl), 7.38 (m, 4H, o-H, m-H, 7-Phenyl), 7.50 (m, 1H, p-H, Phenyl), 7.52 (br. s, $\left.2 \mathrm{H}, \mathrm{NH}_{2}\right), 7.56\left(\mathrm{~m}, 2 \mathrm{H}, \mathrm{m}-\mathrm{H}\right.$, Phenyl), $7.63(\mathrm{~m}, 2 \mathrm{H}, \mathrm{o}-\mathrm{H}$, Phenyl), 7.82 (s, 1H, olefin. $\mathrm{H}) ;{ }^{13} \mathrm{C}$ NMR (DMSO- $\left.d_{6}\right): \delta=41.08$ (C-7), 63.85 (C-6), 87.78 (C-8), 115.86, 118.58 (6-CN, 8-CN), 118.76 (C-2), 128.01 (p-C, 7-Phenyl), 128.09 (o-C, 7-Phenyl), 128.8 (m-C, 7-Phenyl), 129.51 (m-C, Phenyl), 130.12 (o-C, Phenyl), 130.61 (p-C, Phenyl), 131.79 (olefin. CH), 132.83 (i-C, Phenyl), 141.69 (i-C, 7-Phenyl), 124.74 (C-8a), 147.82 (C-5), 165.26 (C-3); MS, m/z (\%), 382.3 $\left(\mathrm{M}^{+}, 100\right), 334.3(17)$.

\% Yields: Method A (Nil), Method B (Nil), Method C (63), and Method D (68).

\section{Synthesis of phthalazine derivatives (13a-c)}

Method A. A mixture of benzylidene-malononitrile (1) (1.54 g, $10.0 \mathrm{mmol}$ ), pyridazine derivatives 12a-c $(10.0 \mathrm{mmol}$ of each) in $50 \mathrm{~mL}(96 \%)$ ethanol in the presence of catalytic amount of chitosan was stirred overnight and the product was purified by recrystallization from ethanol.

Method B. A mixture of same components in $50 \mathrm{~mL}(96 \%)$ ethanol in the presence of piperidine was stirred overnight and the crude product was recrystallized from ethanol.

5-Amino-3-(4-chloro-phenyl)-4-oxo-7-phenyl-3,4-dihydro-phthalazine-6-carbonitrile $\quad$ (13a). ${ }^{13}$ This compound was obtained as yellow crystals; IR (KBr): $v=1603$ ( $\mathrm{Ar} \mathrm{C}=\mathrm{C}), 1649(\mathrm{C}=\mathrm{C}$ ), $2211(\mathrm{CN}), 3329,3472\left(\mathrm{NH}_{2}\right) \mathrm{cm}^{-1},{ }^{1} \mathrm{H}$ NMR (DMSO-d $): \delta=4.02\left(\mathrm{~s}, 2 \mathrm{H}, \mathrm{NH}_{2}\right), 7.44-7.64(\mathrm{~m}$, 9H, Ar-H), 8.44 (s, $1 \mathrm{H}, 1-\mathrm{H}) ;{ }^{13} \mathrm{C}$ NMR (DMSO-d $\left.)_{6}\right): \delta=97.06$ (C-6), 115.08, 118.32, 128.03, $129.76,130.36,130.48,130.58,131.25,140.82,143.15$ (CN, Ar-C, partly superimposed), 165.45 (CO); MS, m/z (\%), $338.2\left(\mathrm{M}^{+}, 100\right), 77$ (18).

\% Yields: Method A (65), Method B (68).

5-Amino-3-(4-chloro-phenyl)-8-methyl-4-oxo-7-phenyl-3,4-dihydro-phthalazine-6-carbonitrile (13b). ${ }^{13}$ This compound was obtained as yellow crystals; IR $(\mathrm{KBr}): v=1607$ ( $\left.\mathrm{Ar} \mathrm{C}=\mathrm{C}\right), 1648$ $(\mathrm{C}=\mathrm{C}), 2211(\mathrm{CN}), 3323,3466\left(\mathrm{NH}_{2}\right) \mathrm{cm}^{-1},{ }^{1} \mathrm{H}$ NMR (DMSO-d $): \delta=2.16(\mathrm{~s}, 3 \mathrm{H}, \mathrm{Me}), 4.37(\mathrm{~s}$, $\left.2 \mathrm{H}, \mathrm{NH}_{2}\right), 7.36-8.61(\mathrm{~m}, 9 \mathrm{H}, \mathrm{Ar}-\mathrm{H}), 8.61(\mathrm{~s}, 1 \mathrm{H}, 1-\mathrm{H}) ;{ }^{13} \mathrm{C}$ NMR (DMSO-d 6$): \delta=16.44\left(\mathrm{CH}_{3}\right)$, 98.85 (C-6), 112.65, 118.05, 120.24, 127.95, 129.79, 130.51, 133.99, 138.43, 139.54, 143.15, 
151.95, 152.99 (CN, Ar-C, partly superimposed), 161.80 (pyrid. $\mathrm{C}=\mathrm{O}$ ); $\mathrm{MS}, \mathrm{m} / \mathrm{z}(\%), 352.2\left(\mathrm{M}^{+}\right.$, 100), 77 (22).

\% Yields: Method A (55), Method B (61).

5-Amino-3-(4-chloro-phenyl)-6-cyano-4-oxo-7-phenyl-3,4-dihydro-phthalazine-1-carboxylic acid ethyl ester (13c). ${ }^{12}$ This compound was obtained as yellow crystal; IR (KBr): $v=1664$ (amide $\mathrm{C}=\mathrm{O}$ ), 1726 (ester $\mathrm{C}=\mathrm{O}), 2212(\mathrm{CN}), 3315,3451\left(\mathrm{NH}_{2}\right) \mathrm{cm}^{-1} ;{ }^{1} \mathrm{H}$ NMR (DMSO- $\left.d_{6}\right): \delta=$ $1.46\left(\mathrm{t}, 3 \mathrm{H}, \mathrm{CH}_{3}\right), 4.07$ (s, 2H, $\left.\mathrm{NH}_{2}\right), 4.13\left(\mathrm{q}, 2 \mathrm{H}, \mathrm{CH}_{2}\right), 7.21-7.61(\mathrm{~m}, 9 \mathrm{H}, \mathrm{Ar}-\mathrm{H}) ;{ }^{13} \mathrm{C}$ NMR (DMSO- $\left.d_{6}\right): \delta=15.82\left(\mathrm{CH}_{3}\right), 63.96\left(\mathrm{H}_{2}\right), 97.02(\mathrm{C}-6), 114.06,111.85,118.00,130.20,130.32$, $130.74,131.41,133.31,134.86,138.37,139.67,141.53,152.45,155.56(\mathrm{CN}$, Ar-C, partly superimposed), 161.76 (amide $\mathrm{C}=\mathrm{O}$ ), 164.36 (ester $\mathrm{C}=\mathrm{O})$; $\mathrm{MS}, \mathrm{m} / \mathrm{z}(\%), 444.2\left(\mathrm{M}^{+}, 100\right), 388.2$ (27), 90.0 (6).

\% Yields: Method A (71), Method B (76).

2-Amino-4,6-diphenyl-benzene-1,3-dicarbonitrile (17). ${ }^{45}(1.54 \mathrm{~g}, 10 \mathrm{mmol})$ of benzylidenemalononitrile (1) and $(1.20 \mathrm{~g}, 0.01 \mathrm{~mol})$ of acetophenone mixed in $50 \mathrm{~mL}(96 \%)$ ethanol in presence of piperidine was refluxed for $4 \mathrm{hrs}$ and treated by the usual previously described treatment.

The product 17 was obtained as yellow crystals; IR $(\mathrm{KBr}): v=1594(\mathrm{Ar} \mathrm{C}=\mathrm{C}), 2145,2215$ (2 $\mathrm{CN}$ ), 3379, $3480\left(\mathrm{NH}_{2}\right) \mathrm{cm}^{-1}$; ${ }^{1} \mathrm{H}$ NMR (DMSO-d $\left.d_{6}\right): \delta=6.80$ (s, $\left.1 \mathrm{H}, 5-\mathrm{H}\right), 6.82$ (br. s, $2 \mathrm{H}, \mathrm{NH}_{2}$ ), 7.52 (m, 6H, $m-\mathrm{H}, p-\mathrm{H}$, Phenyl), $7.63\left(\mathrm{~m}, 4 \mathrm{H}, o-\mathrm{H}\right.$, Phenyl); ${ }^{13} \mathrm{C}$ NMR (DMSO- $\left.d_{6}\right): \delta=94.1$ (C3), 116.0, 118.5 (C-5, CN), 128.5, 128.7 (o-C, m-C, Phenyl), 129.4 (p-C, Phenyl), 137.5 (i-C, Phenyl), 149.9 (C-4), 154.1 (C-2); MS, m/z (\%), 295.2 (M+, 100), 268.1 (17), 77 (4).

\% Yields: Method A (43), Method B (60).

\section{6-Amino-2-dicyanomethylene-4-phenyl-1,2-dihydropyridine-3,5-dicarbonitrile (20) ${ }^{18}$}

Method A. (1.54 g, $10.0 \mathrm{mmol})$ of benzylidene-malononitrile (1) and (1.32 g, $10.0 \mathrm{mmol}) 3$ amino-2-cyanopent-2-enedinitrile were mixed in $50 \mathrm{~mL}(96 \%)$ ethanol in the presence of catalytic amount of chitosan was refluxed for $4 \mathrm{~h}$ and treated by the usual way.

Method B. A mixture of same components in $50 \mathrm{~mL}(96 \%)$ ethanol in the presence of piperidine was refluxed for $4 \mathrm{~h}$. The product was recrystallized from ethanol.

Product 20 was obtained as yellow crystals; IR (KBr): $v=1644(\mathrm{C}=\mathrm{C}), 2218(\mathrm{CN}), 3309,3372$ $\left(\mathrm{NH}_{2}\right) \mathrm{cm}^{-1} ;{ }^{1} \mathrm{H}$ NMR (DMSO- $\left.d_{6}\right): \delta=5.90$ (br. s, $\left.3 \mathrm{H}, \mathrm{NH}, \mathrm{NH}_{2}\right), 7.41$ (m, $2 \mathrm{H}, \mathrm{o}-\mathrm{H}$, Phenyl), $7.51\left(\mathrm{~m}, 3 \mathrm{H}, \mathrm{m}-\mathrm{H}, p-\mathrm{H}\right.$, Phenyl); ${ }^{13} \mathrm{C}$ NMR (DMSO- $\left.d_{6}, 295 \mathrm{~K}\right): \delta=43.8\left(\mathrm{C}(\mathrm{CN})_{2}\right), 80.8(\mathrm{C}-5)$, 85.5 (C-3), 115.6, 116.0 (3-CN, 5-CN), 120 (broad, $\mathrm{C}(\mathrm{CN})_{2}$ ), 128.3 (m-C, Phenyl), 128.5 (o-C, Phenyl), 129.8 (p-C, Phenyl), 135.4 (i-C, Phenyl), 157.7 (C-6), 160.1 (C-2), 160.5 (C-4). ${ }^{13} \mathrm{C}$ NMR (DMSO- $\left.d_{6}, 328 \mathrm{~K}\right): \delta=44.0\left(\mathrm{C}(\mathrm{CN})_{2}\right), 80.9(\mathrm{C}-5), 85.7(\mathrm{C}-3), 115.6,116.0(3-\mathrm{CN}, 5-\mathrm{CN})$, $119.6\left(\mathrm{C}(\mathrm{CN})_{2}\right), 128.3,128.4$ (o-C, m-C, Phenyl), 129.7 (p-C, Phenyl), 135.5 (i-C, Phenyl), 157.7 (C-6), 160.3, 160.5 (C-2, C-4); MS, m/z (\%), 284.1 (M+, 100), 165.1 (16).

\% Yields: Method A (63), Method B (68). 


\section{Acknowledgements}

The support of this work by University of Kuwait through research grant (SC04/06) and the facilities of Analab/SAF through research grant (GC01/01), (GC01/03) and (GS03/01) are gratefully acknowledged.

\section{References}

1. Elnagdi, M. H.; Abed, N. M.; Elmoghayar, M. R. H.; Fleta, D. H. Indian J. Chem. 1976, 14B, 422.

2. Elmoghayer, M. R. H.; Khalifa, M. A. E.; Ibraheim, M. K. A.; Elnagdi, M. H. Monatsh. Chem. 1982, 113, 53.

3. Elgemeie, G. E. H.; Elees, S. A.; Elsakka, I.; Elnagdi, M. H. Z. Naturforsch 1983, 38B, 639.

4. (a) Elgemeie, G. E. H.; Sallam, M. M. M.; Sherif, S. M.; Elnagdi, M. H. Heterocycles 1985, 23, 3107. (b) Elnagdi, M. H.; Abdel-Motaleb, R. M.; Mustafa, M.; Zayed, M. F.; Kamel, E. M. J. Heterocyclic Chem. 1987, 24, 1677.

5. Nawwar, G. A. M.; Osman, S. A.; El-Bayouki, K. A. M.; Elgemeie, G. E. H.; Elnagdi, M. H. Heterocycles 1985, 23, 2983.

6. (a) Abdou, S.; Fahmy, S. M.; Sadek, K. U.; Elnagdi, M. H. Heterocycles 1981, 16, 2177. (b) Elnagdi, M. H.; Abdel-Aal, F. A.; Yassin, Y. M. J. Prakt. Chem. 1989, 331, 971.

7. Elnagdi, M. H.; Maksoud, F. A.; Abdel-Aal, F. A.; Hafez, E. A.; Yassin, Y. M. Z. Naturforsch 1989, 44B, 683.

8. Elmoghayar, M. R. H.; Ibraheim, M. K. A.; Elghandour, A. H. H.; Elnagdi, M. H. Synthesis 1981, 635.

9. Sadek, K. U.; Mourad, A. F. E.; Abd-Elhafeez, A. E.; Elnagdi, M. H. Synthesis 1983, 739.

10. Elnagdi, M. H.; Elmoghayar, M. R. H.; Elghandour, A. H. H.; Sadek, K. U. Sulfur Lett. 1989, 9, 109.

11. Elnagdi, M. H.; Erian, A. W.; Sadek, K. U; Seleim, M. A. J. Chem. Res. (S) 1990, 148.

12. Enagdi, M. H.; Abdelrazek, F. M.; Ibrahim, N. S.; Erian, A. W. Tetrahedron 1989, 45, 3597.

13. Alsaleh, B.; Helmy, N. M.; El-Apasery, M. A.; Elnagdi, M. H. J. Heterocyclic Chem. 2006, 43, 1575.

14. El-Fahham, H. A.; Abdel-Galil, F. M.; Rizk, Y. R.; Elnagdi, M. H. J. Heterocyclic Chem. 1983, 20, 667.

15. Kandeel, E. M.; Baghos, V. B.; Mohareb, R. M.; Elnagdi, M. H. Arch. Pharm. 1983, 316, 713.

16. Elagami, A. A.; Sewilam, S. Z.; El-Taweel, F. M. A.; Elnagdi, M. H. Collect. Czech. Chem. Commun. 1988, 53, 1534. 
17. Elagamey, A. A.; El-Taweel, F. M. A.; Sowellim, S. Z.; Sofan, M. A.; Elnagdi, M. H. Collect. Czech. Chem. Commun. 1990, 55, 524.

18. Elagamey, A. A.; El-Taweel, F. M. A.; Khodeir, M. N. M.; Elnagdi, M. H. Bull. Chem. Soc. Jpn. 1993, 66, 464.

19. Sofan, M. A.; El-Taweel, F. M. A.; Elagamy, A. A.; Elnagdi, M. H. Liebigs Ann. Chem. 1989, 935.

20. Elnagdi, M. H.; Ghozlan, S. A. S.; Abdelhamid, I. A. ARKIVOC, 2008, (x), 54.

21. (a) Kumar, B. S.; Sirinivasulu, N.; Udupi, R. H.; Rajitha, B.; Reddy, Y. T.; Reddy, P. N.; Kumar, P. S. J. Heterocyclic Chem. 2006, 43, 1691. (b) Tu, S. J.; Wei, X.; Zong, Z. J. Chem. Res. 2006, 228-230.

22. Maggi, R.; Ballini, R.; Sortori, G.; Sortori, R. Tetrahedron Lett. 2004, 45, 2297.

23. Tikhonov, B. B.; Sul'man, E. M.; Sidorov, A. I.; Manaenkov, O. V., Russ. Patent, RU 2288033, 2006.

24. Isaeva, V.; Sharf, V.; Nifant'ev, N.; Chernestskii, V.; Dykh, Zh. J. Mol. Catal. 1994, 87, 177.

25. Yin, M. Y.; Yuan, G. L.; Wu, Y. Q.; Huang, M. Y.; Jiang, Y. Y. J. Mol. Catal. 1999, 147, 93.

26. Jin, J. J.; Chen, G. C.; Huang, M. Y.; Jiang, Y. Y. React. Polym. 1994, 23, 95.

27. Yuan, G. L.; Yin, M. Y.; Jiang, T. T.; Huang, M. Y.; Jiang, Y. Y. J. Mol. Catal. 2000, $159,45$.

28.Zeng, X.; Zhang, Y.; Shen, Z. J. Polym. Sci., Part A: Polym. Chem. 1997, 35, 2177.

29. Hu, D. D.; Shi, Q. Z.; Tang, Z. X.; Fand, Y.; Kennedy, J. F. Carbohydr. Polym. 2001, 45,385 .

30. Quignard, F.; Choplin, A.; Domard, A. Langmuir 2000, 16, 9106.

31. Buisson, P.; Quignard, F. Aust. J. Chem. 2002, 55, 73.

32. Guibal, E. Prog. in Poly. Sci. 2005, 30, 71.

33. Elgemeie, G. H.; Regaila, H. A.; Shehata, N. J. Chem. Soc., Perkin Trans. 1 1990, 1, 1267.

34. Gewald K.; Schill, W. J. Prakt. Chem. 1971, 313, 678.

35. Penades, S.; Kisch, H.; Tortschanoff, K.; Margaretha, P.; Polansky, O. E. Ger. Monatsh. Chem. 1973, 104, 447.

36. El-Sakka, I. A.; El-Kousy, S. M.; Kandil, Z. E. J. Prakt. Chem. 1991, 333, 345.

37. Abdel-Latif, F. Gazz. Chim. Ital. 1991, 121, 9.

38. Al-Mousawi, S. M.; Elkholy, Y. M.; Mohammad, M. A.; Elnagdi, M. H. OPPI 1999, 31, 305.

39. Madkour, H. M. F.; Mahmoud, M. R.; Nassar, M. H.; Habashy, M. M. J. Chin. Chem. Soc., 2000, 47, 937.

40. El-Hag Ali, G. A. M.; Khalil, A.; Ahmed, A. H. A.; El-Gaby, M. S. A. Acta Chim Solv. 2002, 49, 365.

41. Abdelrazek, F. M.; Michael, F. A.; Mohamed, A. E. Arch. Pharm. 2006, 339, 305.

42. Ghozlan, S. A. S.; Abdelhamid, I. A.; Elnagdi, M. H. Arkivoc 2006, (xiii), 147. 
43. Mowry, D. T. J. Am. Chem. Soc. 1943, 65, 991.

44. Hafiz, I. S. A.; Rashad, M. E. E.; Mahfouz, M. A. E.; Elnagdi, M. H. J. Chem. Res. 1998, (s), 690-691. Ibid. (m) 2946.

45. El-Torgoman, A. M.; Hafez, E. A.; El-Kousy, S. M.; Elnagdi, M. H. J. Chem. \& Industry 1987, 60-67. 